\title{
BMJ Open Quality Evaluating a community respiratory physiotherapy service for children with neurodisability
}

\author{
Samantha Smith (D , ${ }^{1}$ Moira Flanigan, ${ }^{1}$ Sarah Haynes, ${ }^{2}$ Anastasia Michael, ${ }^{2}$ \\ Toni Wolff (i) ${ }^{3}$
}

To cite: Smith S, Flanigan M, Haynes S, et al. Evaluating a community respiratory physiotherapy service for children with neurodisability. BMJ Open Quality 2022;11:e001683. doi:10.1136/ bmjoq-2021-001683

- Additional supplemental material is published online only. To view, please visit the journal online (http://dx.doi.org/10. 1136/bmjoq-2021-001683).

Received 21 September 2021 Accepted 12 February 2022

Check for updates

(c) Author(s) (or their employer(s)) 2022. Re-use permitted under CC BY-NC. No commercial re-use. See rights and permissions. Published by BMJ.

${ }^{1}$ The Children's Development Centre, Nottinghamshire Healthcare NHS Foundation Trust, Nottingham, UK

${ }^{2}$ The Children's Development Centre, Nottingham University Hospitals NHS Trust,

Nottingham, UK

${ }^{3}$ The Children's Development Centre, Nottingham Children's Hospital, Nottingham, UK

Correspondence to Samantha Smith; samantha.smith@nottshc. nhs.uk

\section{ABSTRACT}

Background Children with neurodisability are at an increased risk of respiratory problems and complications, which often result in prolonged, frequent hospital admissions and are the biggest cause of mortality in this client group. The Children's Community Respiratory Physiotherapy Service (CCRPS) was established in 2010 to support children with severe neurodisabilities at home during acute chest infections and to prevent emergency department attendances and hospital admissions. This service evaluation looked at patient/parent satisfaction and prevented admissions to ensure clinical and costeffectiveness, despite the rising demand for the service. Methods Over a 3-month period, patients and parents/ carers on the CCRPS caseload were given a Picker feedback survey following 100 emergency visits from the team. The number of prevented hospital admissions for respiratory tract infection over 12 months (April 2019March 2020) was identified from existing CCRPS data and hospital admissions costs saved were estimated.

Results The Picker survey responses were extremely positive with all respondents reporting that they felt well looked after and that the main reason for the emergency visit was dealt with well. Based on key indicators, the CCRPS prevented 182 hospital admissions for respiratory tract infection in 2019/2020, equating to 1638 bed days and estimated cost savings ranging between $£ 751728$ and $£ 1009986$.

Conclusions The Picker survey response demonstrates the positive impact that the CCRPS has on both quality of life and experience for patients and families. The CCRPS rapid response service prevents hospital admissions for respiratory tract infections in children and young people with severe neurodisability and the cost savings from admissions prevented allows the service to more than pay for itself.

\section{BACKGROUND}

Innovations and developments in healthcare have led to an increasing population of children and young people (CYP) living with complex neurodisability and life-limiting conditions (LLCs). Recent data show that the prevalence of children with LLCs, particularly those with neurodisability and congenital abnormalities has increased in England from 26.7 per 10000 in 2001 to 66.4 per 10000 in $2017 / 2018^{1}$ and this trend is set to continue. ${ }^{2}$

\section{Key messages}

\section{What is already known on this topic?}

- We know children with medical complexity account for a substantial proportion of healthcare costs, often driven by multiple admissions, lengthy hospital stays and readmissions.

- We know that there is an increasing demand for specialist paediatric respiratory care within the community as the population of severely disabled children increases.

- An early study of this service 10 years ago with only 34 children demonstrated that a community respiratory physiotherapy service can reduce acute hospital admissions, but there was a need to understand how this translates to a larger caseload across a broader age range.

\section{What this study adds?}

- This study adds patient and family feedback on a community respiratory physiotherapy service, highlighting how such a service can affect the whole family.

- This study demonstrates the hospital admission avoidance figures, and cost savings that can be achieved across a much bigger caseload than previously shown.

\section{How this study might affect research, practice or policy?}

- This study provides valuable information to support business cases for a similar service in other regions and for other age groups, promoting an equitable service across the country and beyond.

Children with severe neurodisability are at increased risk of respiratory complications and such problems are a common cause of morbidity and mortality with frequent, prolonged hospital admissions and high healthcare resource use. ${ }^{3}$ Respiratory complications account for the highest proportion of early deaths among this population ${ }^{4}$ and a national cohort study in 2017 showed that CYP with LLCs accounted for $72 \%$ of paediatric intensive care unit (PICU) bed-days and $73 \%$ of deaths in PICU. ${ }^{5}$ 
Expanding service provision and improving quality of life and experience for this patient group were identified as key performance indicators in the UK NHS National Outcomes Framework, ${ }^{6}$ and NHS Long Term Plan. ${ }^{7}$ The commissioning and development of specialist services which are patient-centred, cost-effective and sustainable is of critical importance for the National Health Service (NHS) in a climate with ever-increasing pressures. It has been demonstrated that specialist respiratory physiotherapy treatment can be highly effective in the acute and long-term management of CYP with complex disabilities and recurrent or persistent respiratory illness ${ }^{89}$ and offering these services within the community improves patient experience by keeping CYP closer to home and with their families. ${ }^{10-12}$

The 2020 consensus statement on prevention and management of respiratory disease in young people with cerebral palsy states that this client group should have access to respiratory physiotherapy and personalised chest clearance programmes when needed both as preventative and acute treatment measures. ${ }^{13}$

The Nottinghamshire Children's Community Respiratory Physiotherapy Service (CCRPS) was established in 2010 with one whole time equivalent highly experienced Specialist Respiratory Physiotherapist for Nottingham City, to reduce hospital admissions and emergency department (ED) attendances, improving outcomes, quality of life and experience for CYP with complex neurodisability.

The service provides individualised respiratory physiotherapy care plans including chest clearance programmes, training to parents and the professional carers in the team around the child, as well as rapid respiratory assessment and treatment in the community in the event of an acute deterioration during weekdays.

A typical rapid response visit consists of a thorough respiratory assessment including assessment of the child's vital signs, clinically reasoned chest physiotherapy airway clearance treatment such as manual techniques, nebulisation therapy, mechanical insufflation-exsufflation, high frequency chest wall oscillation and oropharyngeal and nasopharyngeal suctioning. Sputum samples and nasopharyngeal aspirates are usually taken for microscopy, culture and sensitivity, and virology testing to ensure appropriate treatment. The team includes a physiotherapist who is a non-medical prescriber who can prescribe antibiotics, bronchodilators, mucolytics or anti-inflammatory agents if needed. The visit always concludes with the physiotherapist providing the parents/carers with a detailed plan of the chest physiotherapy they should perform in the time until the physiotherapist next visits, and what to do if their child deteriorates.

The physiotherapist has telephone support from the local district community neurodisability paediatricians and the consultant respiratory paediatricians in the local children's hospital.

Since 2010, the service has expanded to three full time specialist physiotherapists and now supports a caseload of 120 CYP from infancy up to 25 years, across Nottingham
City and Nottinghamshire. The area has a population of CYP $0-17$ years of 237500 . The CYP on the caseload have severe neurodisability and complex medical needs. One hundred and five $(88 \%)$ are gastrostomy or nasogastric tube fed, $15(13 \%)$ have a tracheostomy, $25(21 \%)$ are supported by non-invasive ventilation and 102 (84\%) have very severe movement disorders, Gross Motor Function Classification System (GMFCS) level 5 or equivalent for those with neurodegenerative conditions.

An early service evaluation in 2015 identified the CCRPS to be effective in reducing ED attendances, hospital admissions and length of stay for respiratory tract infections. ${ }^{10}$ We now report the results of a further service evaluation which was conducted from 1 April 2019 until end of March 2020 to look at admissions prevented and user satisfaction with the service.

\section{METHOD}

The number of hospital admissions for respiratory tract infection prevented by the CCRPS during the 12-month period April 2019-March 2020 were identified from case note records. A prevented hospital admission for respiratory tract infection was identified when three out of the following five indicators were present at the physiotherapy assessment at the time of the emergency call out visit: fever, respiratory distress, chest auscultation changes, tachycardia or bradycardia and reduced arterial oxygen saturation. These indicators have been used to identify a prevented admission since the service was first established and are based on the Paediatric Early Warning Score system which is used within Nottingham University Hospitals. ${ }^{14}$ This data is collected routinely within the patient records and is fed back to service commissioners on a regular basis.

The number of bed days prevented by the CCRPS during 2019/2020 was calculated assuming an average length of stay at each admission for lower respiratory tract infection (LRTI) of 9 days. The UK NHS Improvement 2020 National tariff ${ }^{15}$ uses an expected average length of stay of 9 days for a child with long-term conditions and comorbidity admitted with an LRTI. We also had preservice data from 2009, when 34 patients had 43 hospital admissions for respiratory tract infection with 383 respiratory admission bed days, ${ }^{10}$ which equates to a mean length of stay of 9 days. If there was more than one emergency contact for the same child within this 9-day timeframe, the additional contacts have not been counted as an admission prevented.

To estimate the potential cost savings as a result of the hospital admissions avoided, we asked the clinical coding team at Nottingham University Hospital which health resource group (HRG) code and complexity and comorbidity (CC) score the CYP on our caseload fall into, according to the NHS Improvement National Tariff. ${ }^{15}$ We gave the coding team an example of an actual admission of one of our patients for LRTI in December 2019 (see box 1). The HRG code allocated for this admission 
Box 1 Comorbidities of the patient whose admission was used as an example to confirm HRG codes and CC scores for our patient group

\section{Comorbidities of patient admitted in December 2019}

- Severe bilateral cerebral palsy with spasticity and dystonia. GMFCS level 5 following hypoxic ischaemic encephalopathy at birth.

Intrathecal baclofen pump in situ.

- Structural focal epilepsy.

- Jejunostomy fed.

- Gut dysmotility.

- Gastro-oesophageal reflux.

- Scoliosis.

Visual impairment.

Wheelchair dependent.

Received physiotherapy.

was PD14A with a CC Score of 11+. The majority of CYP on the CCRPS caseload would score similarly for level of complexity but we also obtained the HRG code for an admission for LRTI of CYP with CC Score 8-10. We then identified the costs of an admission using the UK National tariff ${ }^{16}$ (see table 1 ).

The costs of the CCRPS per annum including staff, equipment and travel were obtained from the service general manager.

The 'Patient Reported Experience Measure (PREM) for urgent and emergency care' is a set of surveys designed to measure the experience of CYP aged 0-16 years (or their parents), in urgent and emergency care settings. These tools were designed in 2012 by the Royal College of Paediatrics and Child Health and the Picker Institute Europe. ${ }^{17}$ To evaluate the CCRPS we adapted, with the support and approval of the Picker team, both the parent and child versions of the tool. The surveys consist of 20 questions and are a mixture of multiple-choice questions, Likert scale questions, demographic questions and open-ended questions.

From 1 November 2019 to 31 January 2020, parents and carers, and where appropriate the child themselves, were asked to anonymously complete a PREM survey at, or shortly after each consecutive emergency home, school or short break unit visit from the CCRPS. The surveys were collected in a sealed envelope either at the end of the visit or at a subsequent visit. The responses to the

Table 1 2019/2020 figures from the national tariff admitted patient care and outpatient procedure prices document

\begin{tabular}{lll}
\hline $\begin{array}{l}\text { HRG } \\
\text { code }\end{array}$ & HRG name & $\begin{array}{l}\text { Cost (£) (completed } \\
\text { consultant episode) }\end{array}$ \\
\hline PD14A & $\begin{array}{l}\text { Paediatric lower respiratory } \\
\text { tract disorders without acute } \\
\text { bronchiolitis with CC Score 11+ }\end{array}$ & 6923 \\
PD14B & $\begin{array}{l}\text { Paediatric lower respiratory } \\
\text { tract disorders without acute } \\
\text { bronchiolitis with CC Score 8-10 }\end{array}$ \\
\hline
\end{tabular}

$\mathrm{CC}$, complexity and comorbidity; HRG, health resource group.
Likert scale questions are reported using simple statistics. The free comments about the emergency care delivered by the service were analysed using thematic analysis.

Ethics approval was not required as this is a service evaluation.

Standards for Quality Improvement Reporting Excellence (SQUIRE) guidelines were used in this paper. ${ }^{18}$

\section{Patient and public involvement}

We adapted a Picker survey which had been already piloted with users. We did not pilot it with our client group before use. We were reassured by the informal verbal feedback of the service users that the survey was appropriate and easy to complete.

\section{RESULTS}

\section{User feedback (PICKER survey)}

One hundred survey forms were given out at rapid response emergency community visits between 1 November 2019 and 31 January 2020. Sixty-six of 100 surveys were returned. In 61 of the surveys, all 18 closeended questions were completed, in 5 there were one or two missing answers, so data from all 66 surveys were analysed.

Sixty-one of sixty-six were completed by the parent/ carer, 3 were completed by the child and parent/carer together and 2 by the child on their own. Forty-three of sixty-six (65\%) CYP who responded or whose parent/ carer responded were male. The median age of the child being seen was 13 years, and the IQR 4-16 years. The majority of CYP were white British/European 35 (63\%) with $17(30 \%)$ being of Asian origin, 2 (4\%) mixed origin, 1 (2\%) black/black British and 1 (2\%) other. English was the main language spoken at home (75\%) with Asian languages in $21 \%$ of respondents and other languages $4 \%$.

The responses to the surveys were extremely positive (see table 2).

The full results from 'Your Child's Emergency Care' Picker survey designed for parents/carers and the full results from the CYP version 'Your Emergency Care' Picker survey can be seen in online supplemental material table $\mathrm{A}, \mathrm{B}$, respectively.

\section{Free comments}

Thirty-three of sixty-six $(50 \%)$ of the respondents gave free comments about what was really good regarding the emergency care given, with most of them giving several comments (online supplemental table $\mathrm{C}$ ). Example comments include 'It is an invaluable service that helps keep our son well and out of hospital, without which would mean more unnecessary hospital visits' and 'fast response, clear plan made for our sons care' and 'always so kind and helpful'. From the comments received, nine themes were identified (see table 3).

Twenty-two of sixty-six (33\%) respondents gave comments to the question 'Was there anything that could have been better?' (online supplemental material table 
Table 2 Survey responses

\begin{tabular}{|c|c|c|c|c|c|c|}
\hline Waiting & $\begin{array}{l}\text { Number of } \\
\text { respondents }\end{array}$ & $\begin{array}{l}\text { We did not } \\
\text { have to wait } \\
\text { at all }\end{array}$ & $\begin{array}{l}\text { The wait was } \\
\text { shorter than } \\
\text { expected }\end{array}$ & $\begin{array}{l}\text { The wait was } \\
\text { about as long } \\
\text { as expected }\end{array}$ & $\begin{array}{l}\text { The wait was } \\
\text { longer than } \\
\text { expected }\end{array}$ & \\
\hline $\begin{array}{l}\text { How did you feel about the } \\
\text { wait time? }\end{array}$ & 66 & 32 (48\%) & 25 (38\%) & $9(14 \%)$ & 0 & \\
\hline Care and treatment & $\begin{array}{l}\text { Number of } \\
\text { respondents }\end{array}$ & $\begin{array}{l}\text { Yes, } \\
\text { completely }\end{array}$ & Yes, sort of & No & Not needed & $\begin{array}{l}\text { Don't } \\
\text { know/can't } \\
\text { remember }\end{array}$ \\
\hline $\begin{array}{l}\text { Did the physiotherapist } \\
\text { explain what they were } \\
\text { doing in a way you could } \\
\text { understand? }\end{array}$ & 66 & $64(97 \%)$ & $1(1.5 \%)$ & 0 & $1(1.5 \%)$ & 0 \\
\hline $\begin{array}{l}\text { Did the physiotherapist do } \\
\text { everything they could to } \\
\text { calm/comfort you or the } \\
\text { CYP? }\end{array}$ & 66 & $61(92 \%)$ & $4(6 \%)$ & 0 & $1(2 \%)$ & 0 \\
\hline
\end{tabular}

\begin{tabular}{|c|c|c|c|c|c|}
\hline $\begin{array}{l}\text { Did you/the CYP } \\
\text { feel at ease with the } \\
\text { physiotherapist? }\end{array}$ & 64 & 61 (95\%) & 3 (5\%) & 0 & \\
\hline $\begin{array}{l}\text { Did the physiotherapist do } \\
\text { everything they could to } \\
\text { help with your/the CYP's } \\
\text { breathing problems? }\end{array}$ & 66 & 56 (85\%) & $1(1.5 \%)$ & $1(1.5 \%)$ & $8(12 \%)$ \\
\hline
\end{tabular}

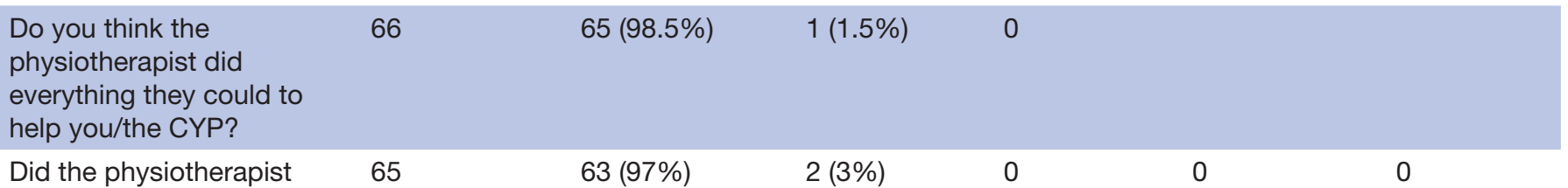

explain what was wrong in a way you could understand?

\begin{tabular}{|lllclll} 
& $\begin{array}{l}\text { Number of } \\
\text { respondents }\end{array}$ & Yes, enough & $\begin{array}{l}\text { Some, but not None, but I } \\
\text { enough }\end{array}$ & $\begin{array}{l}\text { None, but I } \\
\text { would have } \\
\text { liked some } \\
\text { didn't need } \\
\text { any }\end{array}$ & $\begin{array}{l}\text { They didn't } \\
\text { know what } \\
\text { was wrong }\end{array}$ \\
\hline Did you receive enough & 66 & $64(97 \%)$ & $2(3 \%)$ & 0 & 0 & 0
\end{tabular}

information about your/ the CYP's condition and treatment?

\begin{tabular}{|c|c|c|c|c|c|c|}
\hline & $\begin{array}{l}\text { Number of } \\
\text { respondents }\end{array}$ & $\begin{array}{l}\text { Went to } \\
\text { hospital }\end{array}$ & $\begin{array}{l}\text { Went home/ } \\
\text { stayed home }\end{array}$ & Other & & \\
\hline $\begin{array}{l}\text { After the emergency care, } \\
\text { what happened? }\end{array}$ & 65 & $3(5 \%)$ & 38 (58\%) & 24 (37\%) & & \\
\hline Aftercare & $\begin{array}{l}\text { Number of } \\
\text { respondents }\end{array}$ & Yes, definitely & $\begin{array}{l}\text { Yes, to some } \\
\text { extent }\end{array}$ & No & Not needed & $\begin{array}{l}\text { Don't } \\
\text { know/can't } \\
\text { remember }\end{array}$ \\
\hline $\begin{array}{l}\text { Did they tell you what to } \\
\text { watch out for at home after } \\
\text { your/the CYP's care? }\end{array}$ & 62 & 59 (95\%) & 0 & 0 & $3(5 \%)$ & 0 \\
\hline $\begin{array}{l}\text { Did they tell you what to } \\
\text { do or who to contact if you } \\
\text { were worried about anything } \\
\text { after your/the CYP's care? }\end{array}$ & 64 & 64 (100\%) & 0 & 0 & 0 & 0 \\
\hline $\begin{array}{l}\text { Was the main reason for the } \\
\text { emergency care dealt with } \\
\text { well? }\end{array}$ & 65 & 63 (97\%) & $2(3 \%)$ & 0 & 0 & 0 \\
\hline
\end{tabular}


Table 2 Continued

\begin{tabular}{llllll}
\hline Waiting & $\begin{array}{l}\text { Number of } \\
\text { respondents }\end{array}$ & $\begin{array}{l}\text { We did not } \\
\text { have to wait } \\
\text { at all }\end{array}$ & $\begin{array}{l}\text { The wait was } \\
\text { shorter than } \\
\text { expected }\end{array}$ & $\begin{array}{l}\text { The wait was } \\
\text { about as long } \\
\text { as expected }\end{array}$ & $\begin{array}{l}\text { The wait was } \\
\text { longer than } \\
\text { expected }\end{array}$ \\
\hline & $\begin{array}{l}\text { Number of } \\
\text { respondents }\end{array}$ & Very well & Fairly well & Not very well & Not at all well \\
$\begin{array}{l}\text { Overall, how well were you/ } \\
\text { the CYP looked after by the } \\
\text { physiotherapist? }\end{array}$ & 66 & $64(97 \%)$ & $2(3 \%)$ & 0 & 0 \\
\hline
\end{tabular}

Created by the authors.

CYP, children and young people.

D). Four main themes were identified: nothing could be done better 19/22 (86\%), lack of service for post 25 years 2/22 (9\%), lack of 24-hour service 1/22 (5\%) and lack of extended weekend service 1/22 (5\%). Example comments include 'My concern is that the service ends at 25 years old when we will be left with nothing so I can see more hospital admissions in the future' and 'Needs to be a 24-hour service'.

\section{Admissions prevented and cost analysis}

In the 12-month period between April 2019 and March 2020, 182 hospital admissions were prevented by the CCRPS. Assuming an average length of stay (LOS) of 9 days, this equates to 1638 bed days saved.

The majority of the CCRPS caseload would meet the criteria for a CC Score of 11+, however, we have presented a range of possible cost savings based on CC Score 8-10 or $11+$ (see table 4 ). The cost of the CCRPS including staff, travel and equipment is $£ 250000$ per annum.

This gives estimated hospital admissions cost savings for 2019/2020 ranging between £751 728 and £1 009986.

\section{DISCUSSION}

We have presented estimated cost savings for hospital ward admissions with LRTI. However, many of the CYP

Table 3 Themes from respondents' comments about what was really good about emergency care given

\begin{tabular}{ll}
\hline Themes & $\begin{array}{l}\text { Number of free } \\
\text { comments }\end{array}$ \\
\hline Care and advice given & 13 \\
\hline Staff/service & 11 \\
\hline Reassuring and calming & 7 \\
\hline Short wait time & 7 \\
\hline Hospital/GP visits prevented & 5 \\
\hline Detailed explanation/communication & 4 \\
\hline Know the child well & 4 \\
\hline Everything & 4 \\
\hline Medication prescribed & 3 \\
\hline
\end{tabular}

Created by the authors.

GP, general practitioner. on our case load would have been admitted to the PICU rather than a ward. The cost of a critical care bed per day ranges from $£ 849$ to $£ 4824$. ${ }^{19}$ Also, it has been reported that children with neurodisability and medical complexity have an increased risk of a prolonged length of PICU stay $(>15 \text { days })^{20}$ or prolonged hospital ward stays of several weeks ${ }^{13}$ so the cost savings for admissions prevented could be much higher than we have estimated.

Hospital admissions have a negative impact on the quality of life of the child or young person and their family. ${ }^{21}$ The prevented admissions and the enthusiasm for the service from the user feedback suggests that the CCRPS improves the quality of life of the CYP and their families.

There was overwhelmingly positive feedback from the survey with most service users reporting they received good, prompt emergency care, and that they were given advice on signs to look out for and who to contact if they had further worries about their child.

The positive themes identified from the free comments questions show the value of the service to parents/ carers and CYP. The highest proportion of respondents reported 'care and advice' to be a reason why their emergency care was really good. Interestingly, all respondents who cited 'Hospital/GP visits prevented' as a reason for their emergency care being really good were over 16 years of age, perhaps due to these patients/families experiencing multiple hospital admissions prior to the service beginning in 2010. Some respondents said that the physiotherapist being able to prescribe made their emergency

Table 4 Range of cost savings after service costs based on CC scores of $11+$ and 8-10

\begin{tabular}{cll}
\hline & $\begin{array}{l}\text { Admissions prevented } \\
\text { (April 2019-March } \\
\text { 2020) } \times \text { cost completed } \\
\text { consultant episode }\end{array}$ & $\begin{array}{l}\text { Cost savings after } \\
\text { service costs per annum }\end{array}$ \\
\hline $8-10$ & $182 \times £ 5504=£ 1001728$ & $\begin{array}{l}£ 1001728-£ 250 \\
000=£ 751728\end{array}$ \\
& & $£ 1259986-£ 250$ \\
$11+$ & $182 \times £ 6923=£ 1259986$ & $000=£ 1009986$
\end{tabular}

Created by the authors.

$\mathrm{CC}$, complexity and comorbidity. 
care really good as this saved time and stress in getting the help their child needed.

The suggestions for improvement were merely that respondents wanted the service hours to be extended to out of hours, including weekends and bank holidays, indicating how much they value the service. The two respondents who suggested a service for those over age 25 years were parents/carers of young people aged 16 and 22 years. This highlights the apprehension around transition and lack of a similar service for the adult population. There were no criticisms of the service. In response to the suggestions for improvement, extending the service hours to provide $24 / 7$ cover would require the recruitment of several additional specialist therapists and would significantly increase service costs. The service currently operates on 6 days per week over the winter period and extension of this to all year round is being considered. The need for a similar service for young people with severe neurodisability and recurrent respiratory illness has been raised with local health service commissioners and demographic data regarding the numbers of young people who will need such a service in the next 5 years is being collected.

Learning from what patients think about the care they have received is widely accepted as a key to improving healthcare services. Evidence shows that patient experience feedback can shape services to better meet patient need and patient experience is a central outcome for the NHS. ${ }^{22}$

It is important to recognise that the CCRPS does not operate in isolation. The CCRPS is part of the wider multidisciplinary team including paediatric neurologists, respiratory and community neurodisability paediatricians, community nurses, palliative care team, general practitioners and short breaks services. The risk factors for respiratory disease in children with severe neurodisability are multifactorial and a multidisciplinary approach to their management is essential. ${ }^{23}$ Treatment plans must always be in the best interests of the child and aimed at improving quality of life. Many of these CYP will have LLCs and life-threatening conditions and so treatment plans including the family held emergency healthcare/ respiratory escalation plan ${ }^{24}$ are regularly reviewed with the child's lead paediatrician and the CYP and parent/ carers. The CCRPS may be part of the community children's end of life care service and is only withdrawn when the burden of treatment out-ways the benefit, in discussion with child, parents and the multidisciplinary team. Also, there is an increased burden on the families/carers in keeping a severely disabled CYP at home during an acute respiratory infection and there needs to be a flexible home care support package to prevent exhaustion.

\section{Limitations}

Only 66 of 100 completed surveys were returned. There may have been a language barrier for some families and the return rate may have been greater if the survey had been translated for those families whose first language was not English. Also, the CCRPS could have had a more systematic approach to recovering missing responses. However, it has been suggested that the ideal number of responses required to achieve meaningful data for service improvement is $50-100,{ }^{17}$ so 66 returned surveys was adequate.

Although patients and parents/carers were encouraged to answer honestly and the responses were anonymous, we must acknowledge that the families and CYP know the physiotherapists and therefore may not have wanted to criticise them.

\section{CONCLUSION}

This evaluation demonstrates the value of a CCRPS and the positive impact it can have on both the quality of life and experience for both patients and families. As well as providing reassurance and advice, a CCRPS can facilitate families to remain together at home during acute respiratory infection.

The cost savings achieved through prevented hospital admissions for respiratory tract infection by the CCRPS enable the service costs to be covered while still contributing towards NHS savings.

We recommend similar services should be developed for all severely disabled CYP at risk of respiratory tract infection.

With an increasing number on the caseload approaching adulthood, in order to sustain the improved quality of life and maitain the reduced admission rates, the next step for the CCRPS will be to work with local health service commsioners to plan for the provision of a post 25 years service.

Acknowledgements We gratefully acknowledge the contribution of the participants in this study. We thank the Picker Institute for allowing us to adapt and use the surveys for the purpose of this service evaluation. We thank Caroline Adcock and Christine Martin for their support in the initial study design and the collection of survey data.

Contributors SS, MF, SH, AM and TW contributed to the design of the work. SS and MF contributed to the data collection. SS, MF, SH, AM and TW contributed to the data analysis and interpretation. SS contributed to the drafting of the article. SS, MF, SH, AM and TW contributed to the criticial revision of the article. SS, MF, SH, AM and TW contributed to the final approval of the version to be published. The corresponding author attests that all listed authors meet authorship criteria and that no others meeting the criteria have been omitted. SS is the author acting as guarantor.

Funding The authors have not declared a specific grant for this research from any funding agency in the public, commercial or not-for-profit sectors.

Competing interests None declared.

Patient consent for publication Not applicable.

Ethics approval This study involves human participants but medical research council said the study was not considered research by the NHS. Participants gave informed consent to participate in the study before taking part.

Provenance and peer review Not commissioned; externally peer reviewed.

Data availability statement All data relevant to the study are included in the article or uploaded as supplementary information. Not applicable.

Supplemental material This content has been supplied by the author(s). It has not been vetted by BMJ Publishing Group Limited (BMJ) and may not have been peer-reviewed. Any opinions or recommendations discussed are solely those of the author(s) and are not endorsed by BMJ. BMJ disclaims all liability and 
responsibility arising from any reliance placed on the content. Where the content includes any translated material, BMJ does not warrant the accuracy and reliability of the translations (including but not limited to local regulations, clinical guidelines, terminology, drug names and drug dosages), and is not responsible for any error and/or omissions arising from translation and adaptation or otherwise.

Open access This is an open access article distributed in accordance with the Creative Commons Attribution Non Commercial (CC BY-NC 4.0) license, which permits others to distribute, remix, adapt, build upon this work non-commercially, and license their derivative works on different terms, provided the original work is properly cited, appropriate credit is given, any changes made indicated, and the use is non-commercial. See: http://creativecommons.org/licenses/by-nc/4.0/.

ORCID iDs

Samantha Smith http://orcid.org/0000-0002-7458-9052

Toni Wolff http://orcid.org/0000-0002-0206-998X

\section{REFERENCES}

1 Fraser LK, Gibson-Smith D, Jarvis S, et al. Estimating the current and future prevalence of life-limiting conditions in children in England. Palliat Med 2021;35:1641-51.

2 Fraser LK, Gibson-Smith D, Jarvis S. 'Make Every Child Count' Estimating current and future prevalence of children and young people with life-limiting conditions in the United Kingdom. University of York, 2020. Available: https://www.togetherforshortlives.org.uk/ wp-content/uploads/2020/04/Prevalence-reportFinal_28_04_2020. pdf [Accessed Jul 2020].

3 Cohen E, Berry JG, Camacho X, et al. Patterns and costs of health care use of children with medical complexity. Pediatrics 2012;130:e1463-70.

4 Hurley M, Vyas H. Respiratory problems in children with neurodisability. Paediatr Child Health 2015;25:463-6.

5 Fraser LK, Parslow R. Children with life-limiting conditions in paediatric intensive care units: a national cohort, data linkage study. Arch Dis Child 2018;103:540-7.

6 NHS outcomes framework 2016-2017. Available: https://www.gov. uk/government/publications/nhs-outcomes-framework-2016-to-2017 [Accessed Jul 2020].

7 NHS long term plan. Available: https://www.longtermplan.nhs.uk/ online-version/chapter-3-further-progress-on-care-quality-andoutcomes/a-strong-start-in-life-for-children-and-young-people/ redesigning-other-health-services-for-children-and-young-people/ [Accessed Jun 2020].

8 British thoracic Society quality standards for the respiratory management of children with neuromuscular weakness. Available: https://www.brit-thoracic.org.uk/quality-improvement/qualitystandards/neuromuscular-weakness/ [Accessed Nov 2020].

9 Association of Paediatric Chartered Physiotherapists. Commissioning tool for community paediatric respiratory physiotherapy posts, 2017. Available: https://apcp.csp.org.uk/system/files/commissioning_tool_ for_paediatric_community_respiratory_physiotherapy_posts.pdf [Accessed Aug 2020].

10 Wolff A, Griffin H, Flanigan M, et al. Development and evaluation of a community respiratory physiotherapy service for children with severe neurodisability. BMJ Qual Improv Rep 2015;4:u208552.w3411.

11 Turner L, Davidson M, Halfhide C. Families perception of a rapid response community respiratory physiotherapy team. Eur Respir J 2019;54.

12 Michael A, Milner S, Griffin H. G467 rapid response physiotherapy service in patients with life limiting conditions. Arch Dis Child 2019;104:188-9.

13 Gibson N, Blackmore AM, Chang AB, et al. Prevention and management of respiratory disease in young people with cerebral palsy: consensus statement. Dev Med Child Neurol 2021;63:172-82.

14 Chapman SM, Maconochie IK. Early warning scores in paediatrics: an overview. Arch Dis Child 2019;104:395-9.

15 NHS improvement 2020. 2020/21 Annex A: the National tariff workbook. Available: https://www.england.nhs.uk/publication/ national-tariff-payment-system-documents-annexes-and-supportingdocuments/ [Accessed Aug 2020].

16 NHS England national tariff 2019/20. Available: https://www.england. nhs.uk/publication/past-national-tariffs-documents-and-policies/ [Accessed Nov 2020].

17 Royal College of paediatrics and child health. patient reported experience measure (PREM) for urgent and emergency care. Available: https://www.rcpch.ac.uk/resources/patient-reportedexperience-measure-prem-urgent-emergency-care [Accessed Aug 2020].

18 Ogrinc G, Davies L, Goodman D, et al. Squire 2.0 (standards for quality improvement reporting excellence): revised publication guidelines from a detailed consensus process.

19 National Institute for Health and Care Excellence. Putting NICE guidance into practice. resource impact report: end of life care for infants, children and young people with life-limiting conditions: planning and management (NG61). Available: https://www.nice. org.uk/guidance/ng61/resources/resource-impact-report-pdf2729614429 [Accessed Jun 2021].

20 Edwards JD, Houtrow AJ, Vasilevskis EE, et al. Chronic conditions among children admitted to U.S. pediatric intensive care units: their prevalence and impact on risk for mortality and prolonged length of stay $^{*}$. Crit Care Med 2012;40:2196-203.

21 Elema A, Zalmstra TAL, Boonstra AM, et al. Pain and hospital admissions are important factors associated with quality of life in nonambulatory children. Acta Paediatr 2016;105:e419-25.

22 National Institute for Health Research. Improving care by using patient feedback. NIHR Dissemination Centre, 2019.

23 Marpole R, Blackmore AM, Gibson N, et al. Evaluation and management of respiratory illness in children with cerebral palsy. Front Pediatr 2020;8:333.

24 Haynes S, Dorsett C, Wolff T. Writing a good anticipatory care plan for a child with severe disability. Paediatr Child Health 2019;29:441-7. 